\title{
Hommage à Jean-Claude Farcy
}

\section{Frédéric Chauvaud et Marc Renneville}

\section{OpenEdition}

Journals

Édition électronique

URL : https://journals.openedition.org/chs/2925

DOI : $10.4000 /$ chs.2925

ISSN : 1663-4837

\section{Éditeur}

Librairie Droz

\section{Édition imprimée}

Date de publication : 5 août 2021

Pagination : 139-140

ISSN : 1422-0857

\section{Référence électronique}

Frédéric Chauvaud et Marc Renneville, "Hommage à Jean-Claude Farcy 》, Crime, Histoire \& Sociétés / Crime, History \& Societies [En ligne], vol. 25, n¹ | 2021, mis en ligne le 05 août 2021, consulté le 09 novembre 2022. URL : http://journals.openedition.org/chs/2925 ; DOI : https://doi.org/10.4000/chs 2925

Ce document a été généré automatiquement le 9 novembre 2022

Tous droits réservés 


\title{
Hommage à Jean-Claude Farcy
}

\author{
Frédéric Chauvaud et Marc Renneville
}

1 Jean-Claude Farcy (1945-2020) lègue une œuvre scientifique qui se distingue par son ampleur, sa rigueur méthodologique, le défrichage de nouveaux terrains et la mise au point de nombreux instruments de recherche mis au service de la communauté scientifique. Ses premiers travaux s'inscrivent dans le cadre de l'histoire rurale avec une thèse de doctorat portant sur la paysannerie beauceronne ${ }^{1}$. Cette société paysanne qu'il connait bien devient son laboratoire ${ }^{2}$, il explore des sources peu ou pas utilisées, il ouvre des pistes qu'il suivra par la suite, comme l'atteste notamment sa contribution au volume dirigé par Alain Corbin sur l'histoire des loisirs ${ }^{3}$. En 1987, Jean-Claude Farcy devient chercheur au CNRS, rattaché au Centre d'histoire de la France contemporaine de l'Université de Paris-X Nanterre. Il entreprend alors la constitution d'un Guide des archives judiciaires et pénitentiaires, partant de la réforme de l'an VIII, qui voit se mettre en place le système judiciaire des XIX et XX ${ }^{\mathrm{e}}$ siècles, et s'arrête en 1958, au moment de la réforme des juridictions supprimant les justices de paix et créant les Tribunaux de Grande instance. Publié aux éditions du CNRS en 1992, l'ouvrage devient indispensable. Après ce Guide, Jean-Claude Farcy entreprend la confection d'une Bibliographie de l'histoire de la Justice ${ }^{4}$. Désormais rattaché au Centre Georges Chevrier, Université de Bourgogne, il fait preuve dans la plus extrême modestie d'une inlassable activité. En 2001, il publie une synthèse sur trois décennies de recherche sur l'histoire de la justice française à l'époque contemporaine ${ }^{5}$. L'histoire de la justice était alors une histoire jeune et plusieurs possibilités s'offraient à elle mais l'essor récent pouvait s'expliquer à la fois par le renouvellement de l'histoire et l'ouverture de nouveaux chantiers mais aussi par la place grandissante que la justice occupait dans la société. Une grande partie des travaux disponibles portait sur la criminalité et après avoir présenté un inventaire, il convenait de faire le point sur les perspectives de recherche. Les normes, les pratiques judiciaires d'une part, les prisons et les pénalités ensuite, la justice et la répression politique pour terminer dessinent un ensemble à la fois réflexif et programmatique. La réception du livre est enthousiaste. Les spécialistes du domaine soulignent que l'ouvrage parvient à assurer la convergence des travaux des historiens du droit davantage préoccupés par les périodes romaine et médiévale et les historiens issus des sciences humaines. Si Jean-Claude Farcy estime que des travaux de très grande 
qualité ont vu le jour, il pense qu'il faut tendre à l'interdisciplinarité et au comparatisme. Une approche globale de la justice impose de dépasser les frontières disciplinaires et doit œuvrer à un effort plus grand de conceptualisation pour cerner l'objet de la justice ${ }^{6}$. À plusieurs reprises, il remet sur le métier des mises au point sur l'histoire de la justice et des sources judiciaires, soit dans des livres personnels, soit dans des ouvrages collectifs. Dans tous ces travaux et publications, son écriture limpide est mise au service d'une érudition prodigieuse mais sans forfanterie. Auteur de travaux sur les pratiques judiciaires (les discours de rentrée, les rapports des procureurs généraux, etc.), les magistrats (prosopographie, procureurs, juge d'instruction, etc.), les dispositifs répressifs (les suites judiciaires de la Commune de Paris, les camps d'internement pendant la Première guerre mondiale, la peine de mort, etc.), les affaires judiciaires (l'affaire Poirier 1871-1874), l'originalité de l'œuvre de notre collègue tient à la combinaison d'une méthodologie exigeante, cherchant toujours, chaque fois que cela est possible, à combiner des données quantitatives et une analyse très fine des acteurs sociaux et de la trajectoire des individus.

2 Jean-Claude Farcy avait rejoint le comité scientifique de Crime, Histoire \& Sociétés/Crime, History \& Societies dès la création de la revue en 1997. Il y était réputé pour rendre en quelques jours les évaluations de textes qu'on lui soumettait, auxquelles il apportait un soin extrême . Il y publia un article ${ }^{7}$ et un grand nombre de compte-rendus d'ouvrages, jusque peu de temps avant son décès.

3 Auteur d'instruments de travail irremplaçables, Chercheur acquis au bien collectif, Jean-Claude Farcy manquera à tous ceux qui ont eu le privilège de le côtoyer. L'homme était aussi généreux qu'il était discret. Nul doute que son œuvre restera centrale dans les travaux consacrés à la justice contemporaine en France.

\section{NOTES}

1. Jean-Claude Farcy, Les paysans beaucerons au XIX siècle, Chartres, Société archéologique d'Eureet-Loir, 1989, 2 tomes, $663 \mathrm{p}$.

2. C'est ainsi que les pages qu'il consacre à la jeunesse, lui permettront ensuite d'écrire un ouvrage de référence: La jeunesse rurale dans la France du XIX ${ }^{e}$ siècle, Éditions Christian, coll. «Vivre L'histoire », Paris, 2004, 220 p.

3. Jean-Claude Farcy, "Le temps libre au village », in Alain Corbin (dir.), L'avènement des loisirs, 1850-1960.

4. Le Guide et la Bibliographie sont désormais accessibles en ligne sur Criminocorpus : https:// criminocorpus.org/fr/outils/\#\#filter=.bibliographie-1789-2011.

5. Jean-Claude Farcy, L'histoire de la justice française de la Révolution à nos jours, Paris, PUF, coll. «droit et justice », 2001, $494 \mathrm{p}$.

6. Son Histoire de la justice en France de 1789 à nos jours, Paris, La Découverte, coll. "Repères ", 125 p. prolonge et synthétise ses travaux.

7. «Le procureur entre l'ordre public et les justiciables : plaintes, procès-verbaux et poursuites pénales à Dijon à la fin du XIX ${ }^{\mathrm{e}}$ siècle », Crime, Histoire \& Sociétés/Crime, History \& Societies, 2005, 9, 1, 79-115. 


\section{AUTEURS}

\section{FRÉDÉRIC CHAUVAUD}

frederic.chauvaud[at]univ-poitiers.fr

MARC RENNEVILLE

marc.renneville[at]cnrs.fr 